
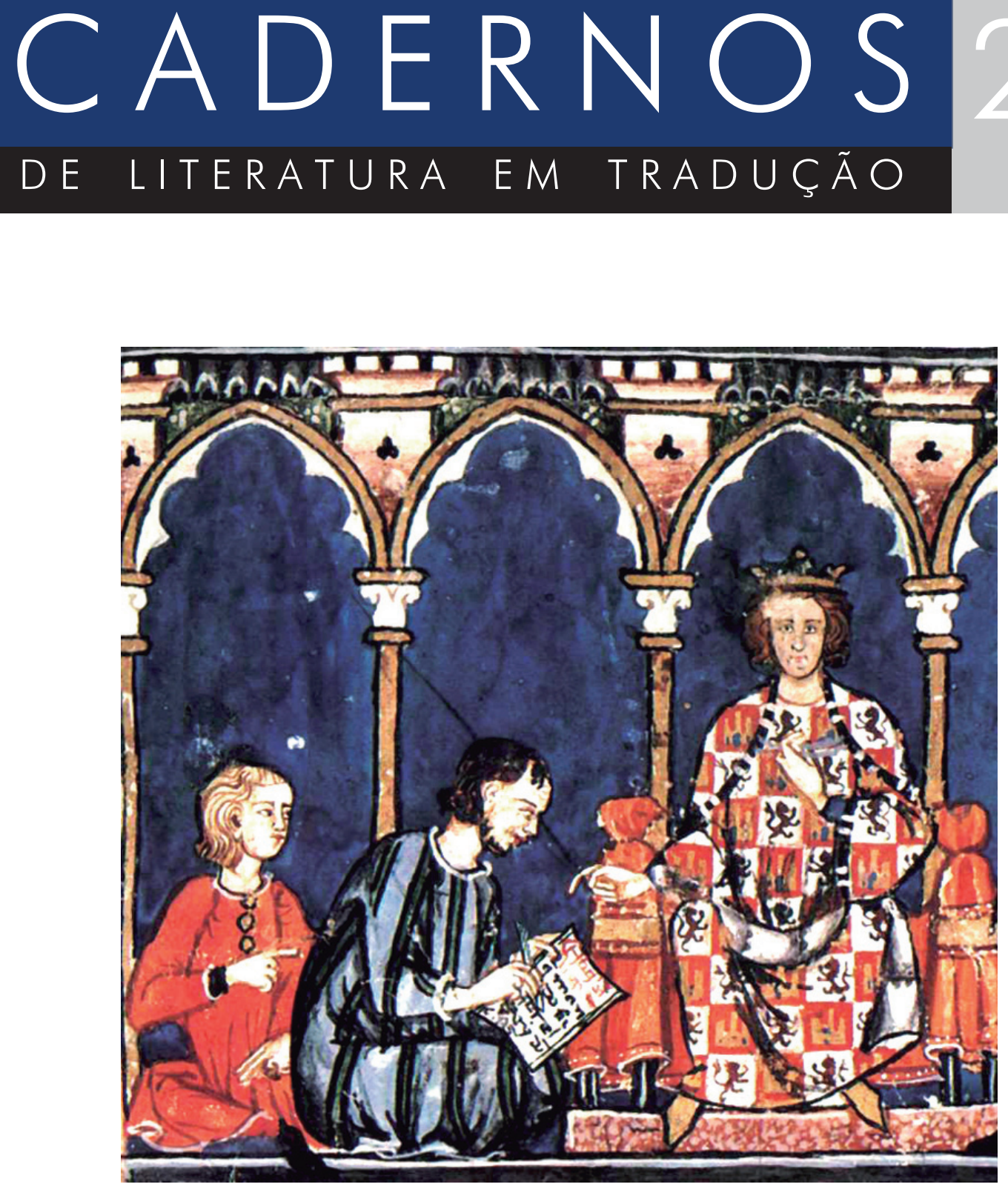

Tradutores da chamada Escola de Toledo com Afonso $X$ de Castela 


\title{
Comentários à tradução do conto "Passing", de Langston Hughes: a Letra e a oralidade no gênero espistolar
}

\author{
Isadora Fortunato
}

Resumo: Neste artigo apresentamos comentários e reflexões referentes à tradução do conto "Passing", presente na obra The Ways of White Folks (1934), de Langston Hughes (1902-1967). Serão analisadas características e definições do gênero epistolar (ALVES, 2015; KOHLRAUSCH, 2015; ROCHA, 2011; TIN, 2005) em relação à maneira como Hughes se apropria ou subverte esta estrutura tradicional em sua narrativa literária; consideramos também conceitos como Letra, a poeticidade do texto literário e as redes significantes (BERMAN, 2013; CHKLOVSKY, 1978 [1917]; PAGANINE, 2013); e, por fim, serão tecidos comentários com análises acerca da representação da oralidade no texto literário na relação linguagem falada e linguagem escrita (BAGNO, 2007; LUCCHESI, 2009).

Palavras-chave: tradução comentada; gênero epistolar; redes significantes; oralidade.

\begin{abstract}
In this article we present commentaries and reflections to our translation of Langston Hughes'(1902-1967) short story "Passing", from the book The Ways of White Folks (1934). Characteristics and definitions of the epistolary genre will be analyzed and considered in relation with how the author approaches the genre and subverts it in his narrative; we also consider concepts such as the Letter, the poeticity of the literary text and the underlying network ofsignifications (BERMAN, 2013; CHKLOVSKY, 1978 [1917]; PAGANINE, 2013); and, lastly, we will comment and analyze the representation of orality in the literary text in the relation between oral and written language. (BAGNO, 2007; LUCCHESI, 2009).
\end{abstract}

Keywords: translation with commentary; epistolary genre; underlying network of significations; orality. 


\section{Introdução}

James Mercer Langston Hughes (1902-1967) foi um escritor que alcançou bastante reconhecimento como um dos principais integrantes do movimento artístico-cultural denominado Harlem Renaissance (1918-1935, aproximadamente) e que possui destaque no sistema literário norte-americano graças à sua produção escrita, principalmente a poética. Mas Langston Hughes também foi um prolífico escritor nos mais diversos campos, escrevendo contos, peças, ensaios, autobiografias, obras sobre a história da literatura afro-americana, músicas, livros infantis, textos humorísticos, colunas de jornal (onde expressava sua opinião sobre um determinado tópico corrente na sociedade da época) e, inclusive, traduções (KUTZINSKI , 2012; RAMPERSAD, 2001, p. xi-xvi).

Aqui analisamos aspectos literários do conto "Passing" e os desafios apresentados a sua tradução para o português brasileiro. Este conto se apresenta como uma carta de um filho à sua mãe e onde ele relata tê-la ignorado ao passar por ela na rua a fim de que não descobrissem sua verdadeira origem (ser um homem de ascendência afro-americana e não branco como ele afirma ser). A partir disso, o narrador relata sua vida e seus remorsos ao usufruir dos privilégios que obtém por ter a pele clara. Este conto faz parte da obra The ways of white folks, uma coletânea de 14 contos, escritos e publicados entre 1931 e 1934 nas revistas Esquire e American Mercury e no jornal The Brooklyn Daily Eagle, e depois reunidos na publicação em livro (GRANT, 1995, p. 44 e 46; OSTROM, 1993, p. 8).

\section{O gênero epistolar e o conto "Passing"}

No sentido etimológico, a palavra Epistola é um termo vindo do grego e que significa "enviado". Já o vocábulo "carta" teria origem nas cartas feitas com papiro (charta), confeccionadas em formato de um pequeno livro. A definição do gênero é proposta em $A$ arte de escrever cartas (2005), organizado por Emerson Tin, onde constam três tratados acerca do gênero epistolar escritos por Anônimo de Bolonha (século XII), Erasmo de Roterdã, filósofo holandês, e Justo Lípsio, humanista flamengo (ambos com tratados do século XVI). De acordo com Anônimo de Bolonha, por exemplo, a carta teria as seguintes características: saudação, narração, petição, captação da benevolência (angariando a atenção do destinatário), conclusão. Entretanto, Erasmo de Roterdã afirma em seu tratado que nem sempre haveria a necessidade de que todos estes elementos fossem 
utilizados. Na listagem dos elementos de uma carta, figuram também a datação e destinatário expressos no início do texto ${ }^{1}$.

No caso de "Passing", é possível notar a mescla do literário com o epistolar no conto com a presença do título do mesmo concomitante a estes elementos específicos do gênero epistolar. Algumas destas características são apresentadas no quadro abaixo:

Quadro 1 - algumas características do gênero epistolar em "Passing"

Texto-fonte
PASSING
Chicago,
Sunday, Oct. 10.

Dear Ma,

I felt like a dog, passing you downtown last night and not speaking to you. You were great, though. Didn't give me a sign that you even knew me, let alone I was your son. If I hadn't had the girl with me, Ma, we might have talked(...) (HUGHES, s.p., 1934).

\section{Texto-alvo \\ PASSANDO}

Chicago,

Domingo, 10 de outubro.

Mamãe,

Me senti um canalha por passar por você ontem à noite no centro da cidade e não falar contigo. Mas você foi incrível. Não deu qualquer sinal de que me conhecia, muito menos de que eu era seu filho. Mãezinha, se eu não estivesse com minha garota, a gente teria conversado. (...)

Unindo as definições dos três tratados, podemos encontrar alguns elementos que compõem o gênero epistolar. Ele é um arranjo linguístico estruturado, ordenado e disposto de maneira correta, que transmite os sentimentos do remetente e pressupõe um tom coloquial e mais leve caso o destinatário faça parte do núcleo de relacionamentos do remetente (família ou amigos). Uma carta deve ser expressa como uma conversação, evocando tudo o que é cotidiano e doméstico e se utilizando de linguagem comum. Pode ser escrita com esmero, mas deve dar a aparência de uma linguagem escrita de improviso. Uma carta deve ter um tamanho exato para não cansar o interlocutor e, ainda assim, transmitir o que deseja através de seu conteúdo.

O gênero epistolar é uma estrutura canônica dentro da literatura, sendo abordada desde a Antiguidade Clássica, tendo em Demétrio, Cícero e Sêneca principais figuras que propuseram conceitos acerca da epistolografia, passando pela

1 Cf. https://brasilescola.uol.com.br/redacao/carta-pessoal.htm. Acesso em: 30mai2020. 
época do Renascimento, na qual havia manuais (como os tratados mencionados acima) que definiam maneiras adequadas de se escrever uma carta a diferentes destinatários e chegando até a literatura, com a apropriação desse gênero textual e sua utilização em obras literárias de várias épocas. A partir das definições e propósitos da carta no gênero literário ou no cotidiano, tentamos compreender como Hughes se apropria desse gênero canônico para propósitos literários e de discussões raciais e sociais.

O gênero epistolar perpassa a história literária. Nota-se uma quantidade de autores ao longo da história literária em vários territórios que se apropriam desse gênero em suas narrativas ficcionais, é possível encontrar este gênero na literatura oitocentista, tendo por exemplos Pamela, de Samuel Richardson (1740), na literatura inglesa; Cartas Persas e Cartas Inglesas, de Voltaire (1721; 1734), na literatura francesa. Podemos recuperar alguns exemplos da literatura brasileira como os romances Clarissa (1933) e Olhai os Lírios do Campo (1938), de Erico Veríssimo; De mim já nem se lembra, de Luiz Rufatto (2007) e K. Relato de uma busca, de Bernardo Kucinski (2016), obras que, por sua vez, se apropriam da carta como recurso literário na totalidade do texto ou apenas parcialmente. .

O gênero epistolar na literatura presentifica sentimentos, pensamentos e questões interiores partilhadas entre remetente e destinatário (KOHLRAUSCH, 2015), traz um senso de intimidade e permite revelar o mundo interior dos personagens, o que sentem e o que pensam (ALVES, 2015, p. 183), aproximando estes últimos e o leitor através da linguagem, da identificação ou empatia geradas através da aparência de cotidiano que a carta evoca.

A questão do $e u$ se revela importante nesta análise, pois este $e u$ se constrói na interação com o outro, a ficção e a realidade se colocam face a face no texto. O texto epistolar suscita um investimento de leitura devido ao seu apelo para a proximidade, para a vida íntima dos personagens e os pensamentos do remetente que se revelam através do texto. É o que Vanessa Rocha (2011, p. 121) atesta com um dos protocolos de leitura do epistolar: a camaradagem que se estabelece não apenas entre remetente e destinatário da carta, mas também na leitura daqueles que não fazem parte deste circuito de comunicação.

Um outro dado importante a ser considerado é a narração como a parte principal de uma carta. Anônimo de Bolonha afirma que a carta sem esse elemento fica incompleta, não transmite a informação que deve carregar (2005 p. 102). E, de fato, o elemento narrativo de uma carta é o que permite que esta seja apropriada pela literatura e que se desenvolva uma história ao contar uma situação ou compartilhar uma experiência. 
A carta pode se destinar entre um e outro e entre um e vários e este aspecto se apresenta de maneira relevante na análise do conto "Passing" porque, ao mesmo tempo em que o leitor se depara com uma carta de um filho para sua mãe, onde assuntos particulares e afetos são demonstrados, também se depara com uma carta de um para vários, onde questões raciais e sociais concernentes à sociedade como um todo são demonstradas e desenvolvidas narrativamente.

Além disso, fato comum mencionado pelos três autores citados acima e no artigo de Rocha (2011) é a carta como uma comunicação de ausentes, ou destinada a um ausente. Em "Passing", este ausente se mostra de forma muito evidente devido ao fato de o filho ter de se separar de sua família, se "passar por branco" (passing for white) para manter um status social mais favorecido enquanto que os irmãos, negros, possuem empregos em que não obtêm muitos rendimentos, e não puderam fazer curso superior como o irmão. Como diz o narrador (remetente) no conto, uma carta não é impedida de circular pelas barreiras raciais, ela permite que dois ausentes possam se encontrar e demonstrar seus sentimentos abertamente. Esses sentimentos e visões compartilhadas, ao serem propostos como narrativa literária, se encontram com o leitor, com a sociedade e promovem uma reflexão sobre a maneira como a injustiça e a opressão em um nível macro afeta os indivíduos no microcosmo familiar.

É possível também considerar uma relação de ausentes entre o autor e o leitor, na qual ambos estão ausentes e compartilham do assunto pelo pacto de leitura realizado entre eles. Além disso, ao demonstrar fatos e sentimentos, é apresentada toda a problemática da discriminação racial e social que afeta aquele contexto, pressupondo um "leitor-destinatário" que irá se envolver na crítica realizada. A partir de uma atmosfera de vida diária, é possível discutir questões sobre a discriminação racial e desigualdade social.

A relação entre ausentes também se dá na tradução, porém com outra faceta. Traduzir este conto é inscrever-se em uma lógica de pressupor ausentes e, ao mesmo tempo, presentificá-los, principalmente o autor, em um novo contexto e em uma nova sociedade. É também presentificar um texto neste contexto atual: esta ação de traduzir o torna sujeito a novas leituras, novos modos de análise e, consequentemente, novas maneiras de reescrita. Este texto agiu sobre o leitor-tradutor, que o reescreve inserido em seu próprio contexto e este mesmo texto irá agir sobre outros leitores de outros contextos e irá suscitar leituras distintas. Esta é a consequência da tradução, provocar uma aproximação de diferentes ausentes em planos sociais e espaciais distintos que o texto-fonte jamais poderia alcançar sem este trabalho. $\mathrm{O}$ ato de povoar ausências e de 
promover encontros (ROCHA, 2011) é o elemento-chave do gênero epistolar e (por que não?) da tradução.

Além disso, o diferencial em "Passing" com relação a sua escrita em carta é a ruptura do silêncio (ROCHA, 2011, p. 111). Este conto dá voz aos indivíduos presentes nas situações vivenciadas, dá corpo àquelas pessoas que as vivem, dá um rosto, nomes, e tempos e lugares, o que também traz o leitor para o texto, pois o traz para aquele espaço-tempo, mesmo este sendo em parte ficcional. E uma carta dá voz aos pensamentos e percepções, corporifica e sonoriza discursos presentes na sociedade como a discriminação racial e de classe nas relações sociais, na família, nas escolas e nas instituições como um todo, e mostra a maneira como a sociedade está construída e atravessada por eles.

\section{A poeticidade na prosa e as redes significantes}

Um questionamento realizado por Regina Kohlrausch (2015, p. 152) acerca do gênero epistolar na literatura se faz relevante para descrever a poeticidade deste gênero na prosa de ficção. Kohlrausch questiona:

Se a essência do literário é a ficcionalização da realidade, marcada por um discurso plurissignificativo, sem o compromisso da veracidade dos fatos, e a carta tem o compromisso dessa veracidade, pois ela é um documento expressivo que informa ao outro acerca da vida do emissor, e que é lida, no momento da recepção, como uma verdade, de que forma pode-se dar a ela um caráter de literário?

De fato, temos em "Passing" um gênero textual que pressupõe uma certa veracidade, um certo "pé" na realidade concreta; a princípio seria então uma prosa sem elementos criativos, preocupada apenas com a mensagem. Mas não é isto o que se verifica no conto. Os elementos critativos, a sua poeticidade está relacionada à própria exposição de elementos do real de uma determinada maneira e também ao uso do que Berman denomina redes significantes (2012, p. 78).

No que se refere à exposição do real a partir de um texto literário em prosa, em $A$ arte como procedimento, Viktor Chklovsky (1978 [1917]) desenvolve uma diferenciação entre a linguagem prosaica e a poética. O teórico propõe que esta última se revela a partir da singularização de um objeto estético, um objeto que é criado na literatura a partir de determinados procedimentos de escrita. No âmbito do signo, a escrita cria uma imagem nova que detém a percepção do leitor e a desautomatiza, cria uma visão, e não o reconhecimento, que é ligado à 
economia das energias (pois reconhecer é poupar as energias da percepção). O teórico afirma que "a imagem poética é um meio de criar uma impressão máxima" (CHKLOVSKY, 1978, p. 42).

Podemos ver a associação entre a linguagem prosaica, caracterizada por Chklovsky como fácil, correta, econômica (assim como uma carta) e a linguagem poética singularizante a partir de um discurso elaborado que associa a linguagem informal e popular (uso repetitivo de mighty e though e do vocativo "Ma", por exemplo) a fatores de singularização que detém a percepção: rede de significantes de termos raciais (mulato, negro, colored, darkies, etc.) o duplo uso da palavra passing (passar-se por branco e passar por alguém), as repetições de $M a$ (como uma interpelação insistente), figura como mire of color ("armadilha da cor"), por exemplo.

Além disso, fatores singularizantes podem ser percebidos na inserção de situações fortes como o fato de um filho ignorar a mãe ao passar por ela na rua para manter a "farsa" de ser branco, com o objetivo de alcançar um status econômico superior; o fato de ele escolher uma futura esposa que vê os afro-americanos apenas sob o estereótipo de alegre/engraçado, ou seja, uma pessoa sem qualquer consciência da problemática racial em que ela está inserida e que se reflete em sua própria fala, tudo isso gera no leitor uma desautomatização, ou seja, o leitor é incluído na lógica da discriminação e do preconceito; a carta aproxima todas essas questões para o contexto do leitor, prende-o nesta rede. O texto faz com que ele inevitavelmente mergulhe nesta situação, sinta e identifique aspectos da realidade ali.

Os postulados de Antoine Berman na obra $A$ tradução e a letra ou o albergue do longínquo (2012) se fazem importantes na análise deste conto. Na obra, Berman faz considerações sobre questões tradutórias com base na defesa da tradução da Letra, ou seja, que os tradutores estejam atentos aos jogos de significantes no texto e não apenas busquem equivalências diretas entre as palavras da língua, que não traduzam apenas o sentido (2012, p. 21). Segundo o autor, a tradução não deve assumir a tendência de desconsiderar os jogos de sentido que os signos estabelecem no texto-fonte; eles devem ser, portanto, reproduzidos no texto traduzido. Ele ainda analisa a questão da pluralidade da Letra e a construção de redes significantes, que reafirmam a(s) temática(s) do texto de maneira subjacente. Ele concebe a princípio a questão da Letra, considerada em sua ambivalência, significante e significado.

Berman também comenta sobre a tradução ter a tendência de deformar esta Letra, de não respeitá-la como parte integrante do texto, necessária para a construção da interpretação, e que precisa ser considerada neste processo a fim de evitar a deformação. Porém Berman afirma que esta deformação não se realiza de maneira propositadamente nociva muitas vezes. Ao contrário, ela é parte das forças 
que atuam sobre o tradutor e seu processo tradutório e se revelam no produto; é parte do que ele denomina tradução etnocêntrica e hipertextual, uma tradução que privilegia a cultura para a qual se traduz e que altera a forma do texto-fonte.

O teórico afirma que a prosa é um gênero caraterizado pela pluralidade de formas e de formas da(s) língua(s) e, assim, a tradução se depara com esta multiplicidade contida em apenas um espaço textual. E se um trabalho tem como foco a atenção apenas ao sentido e ao controle da forma para que seja 'bela', deforma-se a polilogia da prosa (variedade lexical), uma ação que, por sua vez, é menos percebida na poesia. $\mathrm{O}$ autor afirma muito lucidamente que as deformações na poesia são mais bem aceitas e que, se na poesia deve-se respeitar a polissemia (a pluralidade de significados), na prosa deve-se respeitar a polilogia informe (a multiplicidade da letra) (BERMAN, 2012, p. 66-67).

Uma das treze tendências deformadoras listadas pelo autor é a destruição das redes significantes subjacentes. No texto em prosa há um texto que o subjaz, palavras que formam redes abaixo da superfície e contribuem para a mensagem e para a estética, "constitui uma das faces da rítmica e da significância da obra" (BERMAN, 2012, p. 79). Estas redes significantes se relacionam pelas similitudes ou intencionalidade. Uma prosa pode apresentar esta rede e "organizar a falância do texto" (2012, p. 80).

Carolina Paganine, em seu artigo “Tradução comentada: O gótico e a cadeia de significantes” (2013), faz uma análise das redes significantes presentes no conto "Barbara of the House of Grebe", parte da obra A group of Noble Dames (1891), do autor inglês Thomas Hardy. Paganine atesta que este conto apresenta determinadas redes de palavras que apontam para a inscrição do conto no gênero gótico e para a criação do clima próprio deste gênero na narrativa. Isto se transmite de modo subjacente ao texto e ajuda a construir esta interpretação do conto. Segundo ela, a ocorrência de significantes em rede no decorrer da narrativa reafirma a temática para a qual apontam e o efeito que se pretendeu causar, pois “(...) as redes lexicais enfatizam o tema, amarrando-o linguisticamente à tessitura da história narrada" (PAGANINE, 2013, p. 261). No artigo mencionado são expostas, por exemplo, quatro redes significantes relacionadas às temáticas de "horror/medo", "agitação nervosa", "infantilidade/impulsividade" e "desfiguração física" (PAGANINE, 2013, p. 255). Trazemos aqui a título de exemplo a rede de significantes analisada por ela relacionada à temática da "infantilidade/impulsividade":

Ao estado constante de agitação física e mental de Barbara, somam-se as diversas vezes em que o narrador reitera sua imaturidade, o que 
a leva a agir impulsivamente. (...)Assim, as ações de Barbara são qualificadas por expressões tais como "immediate instinct" / instinto imediato" (BHG, S 62), "without much reflection"/"sem muita reflexão" (BHG, \ 73), “impulsiveness"/ "impulsividade” (BHG, \ 75), "infantine tenderness"/ "ternura infantil" (BHG, \145) e "her delicate soul" / sua alma delicada" (BHG, \ 166). (PAGANINE, 2013, p. 259)2.

A questão das redes significantes é muito importante na análise do conto "Passing", pois, em primeiro lugar, é possível perceber a questão da Letra e da multiplicidade da língua logo na superfície do texto. Apresenta-se uma superposição de linguagem oral e linguagem escrita, registro formal e informal, inglês standard (padrão) e o inglês afro-americano ${ }^{3}$ (African American English (AAE)). No conto é possível perceber que Hughes se apropria da linguagem oral e a expressa no texto escrito, o que gera, consequentemente, um texto com um tom fortemente ligado à fala, com um "tom conversacional", característico da carta. Outro exemplo deste polilinguismo (mesmo que tímido neste caso) é a presença da variedade linguística do AAVE em uma sentença ("you was too proud", ao invés de "you were”, o uso do verbo 'was' com o pronome pessoal ‘you'). Assim, é possível perceber que não se tem um texto totalmente uniforme, totalmente obediente à norma padrão de escrita. Logo, uma tradução que se queira respeitosa à Letra e ao leitor da cultura-alvo precisará manter o polilinguismo e não uniformizar o texto-alvo quando ele se apresenta como múltiplo. Podemos verificar estes fatores no exemplo abaixo:

2 Cf. PAGANINE, Carolina. Tradução comentada: O gótico e a cadeia de significantes. Belas Infiéis. Brasília, Vol. 2, No. 1, 2013. pp. 251-264.

3 variedade da língua inglesa falada por pessoas negras tanto nos Estados Unidos e em outros lugares da América. 
Quadro 2 - exemplos: superposição de linguagem oral e linguagem escrita e polilinguismo.

\begin{tabular}{|c|c|}
\hline & Texto-alvo \\
\hline $\begin{array}{l}\text { I'd be glad, though, if I could get away } \\
\text { from Chicago, transferred to the New York } \\
\text { office, or the San Francisco branch of the } \\
\text { firm - somewhere where what happened last } \\
\text { night couldn't ever occur again. It was aw- } \\
\text { ful passing *you* and not speaking. And if } \\
\text { Gladys or Charlie were to meet me in the } \\
\text { street, they might not be as tactful as you were } \\
\text { - because they don't seem to be very happy } \\
\text { about my passing for white. I don't see why, } \\
\text { though. I'm not hurting them any, and I send } \\
\text { you money every week, and help out just as } \\
\text { much as they do, if not more. Tell them not to } \\
\text { queer me, Ma, if they should ever run into me } \\
\text { and the girl friend any place. Maybe it would } \\
\text { have been better if you and they had stayed in } \\
\text { Cincinnati and I'd come away alone when we } \\
\text { decided to move after the old man died. Or at } \\
\text { least we should have gone to different towns, } \\
\text { shouldn't we? } \\
\text { Gee, Ma, when I think of how papa left } \\
\text { everything to his white family, and you couldn't } \\
\text { legally do anything for us kids, my blood boils. } \\
\text { You wouldn't have a chance in a Kentucky } \\
\text { court, I know, but maybe if you'd tried anyway, } \\
\text { his white children would have paid you some- } \\
\text { thing to shut up. Maybe they wouldn't want } \\
\text { it known in the papers that they had colored } \\
\text { brothers. But you was too proud, wasn't you, } \\
\text { Ma? I wouldn't have been so proud. }\end{array}$ & $\begin{array}{l}\text { Na verdade, eu ficaria satisfeito se eu pu- } \\
\text { desse sair de Chicago e ser transferido pro } \\
\text { escritório de Nova Iorque ou pra filial de São } \\
\text { Francisco - algum lugar onde nunca aconte- } \\
\text { cesse o mesmo que na noite passada. Foi hor- } \\
\text { rível passar por *você* e não falar nada. E se } \\
\text { Gladys ou Charlie me vissem na rua, talvez não } \\
\text { fossem tão cuidadosos - porque eles não pare- } \\
\text { cem estar muito contentes com essa história de } \\
\text { eu me passar por branco. Não sei por quê. Não } \\
\text { estou fazendo nada de mal a eles, te mando di- } \\
\text { nheiro toda semana e ajudo tanto quanto eles, } \\
\text { até mais. Diz a eles pra não me envergonha- } \\
\text { rem, mãe, se esbarrarem comigo e com minha } \\
\text { namorada em algum lugar. Talvez fosse melhor } \\
\text { que você e eles tivessem ficado em Cincinnati } \\
\text { e eu tivesse vindo sozinho quando decidimos } \\
\text { nos mudar, depois que o velho morreu. Ou } \\
\text { pelo menos a gente devia ter ido pra cidades } \\
\text { diferentes, né? } \\
\text { Poxa, mãezinha, quando eu paro pra pen- } \\
\text { sar em como o papai deixou tudo pra família } \\
\text { branca dele e você não pôde fazer nada pela } \\
\text { gente na Justiça, meu sangue ferve. Eu sei que } \\
\text { você não ia ter chance no tribunal de Kentucky, } \\
\text { mas, se ainda tivesse tentado, talvez os filhos } \\
\text { brancos lá dele teriam te pago alguma coisa pra } \\
\text { ficar quieta. Talvez eles não fossem querer ver } \\
\text { exposto nos jornais que tinham irmãos de cor. } \\
\text { Mas você foi muito orgulhosa, né, mãezinha? } \\
\text { Eu não teria sido tão orgulhoso. }\end{array}$ \\
\hline
\end{tabular}

Além da questão do polilinguismo, podemos analisar também neste conto a questão das redes significantes que apontam para a temática racial. Há duas redes ligadas a esta temática, uma delas com referente "cor da pele", com 8 significantes, e outra relacionada a ideologias/discursos raciais. Vejamos as duas redes nos quadros abaixo e suas respectivas traduções. 
Quadro 3 - redes significantes e respectivas traduções no conto "Passing"

\begin{tabular}{|l|l|}
\hline "Colored"(10 ocorrências) & "De cor"/ negro \\
\hline "Negro" (2 ocorrências) & "Negro" \\
\hline "Mulatto" (1 ocorrência) & "Mulato" \\
\hline "Black" (1 ocorrência) & "Negro" \\
\hline "Light/ light-skinned" (3 ocorrências) & "Pele clara" \\
\hline "Dark/Darkies" (3 ocorrências) & "Escuro/escurinho" \\
\hline "White" (12 ocorrências) & "Branco" \\
\hline "High yellow" (1 ocorrência) & "Pardo" \\
\hline
\end{tabular}

Quadro 4 - exemplos do texto-fonte e da tradução

\begin{tabular}{|c|c|}
\hline Texto-fonte & Texto-alvo \\
\hline $\begin{array}{l}\text { (...) I'm not as scared as I used to be about } \\
\text { somebody taking me for colored any more just } \\
\text { because I'm seen talking on the street to a Ne- } \\
\text { gro. I guess in looks I'm sort of suspect-proof, } \\
\text { anyway. You remember what a hard time I used } \\
\text { to have in school trying to convince teachers I } \\
\text { was really colored. Sometimes, even after they } \\
\text { met you, my mother, they wouldn't believe it. } \\
\text { They just thought I had a mulatto mammy, I } \\
\text { guess. Since I've begun to pass for white, no- } \\
\text { body has ever doubted that I am a white man. } \\
\text { Where I work, the boss is a Southerner and is } \\
\text { always cussing out Negroes in my presence, } \\
\text { not dreaming I'm one. It is to laugh! }\end{array}$ & $\begin{array}{l}\text { (...) Não sinto mais tanto medo como antiga- } \\
\text { mente de alguém pensar que eu sou de cor só } \\
\text { porque fui visto conversando com um negro } \\
\text { na rua. De qualquer maneira, acho que, quan- } \\
\text { to à minha aparência, estou acima de qualquer } \\
\text { suspeita. Você lembra como era difícil pra mim } \\
\text { na época da escola, tentar convencer os profes- } \\
\text { sores de que eu era realmente de cor. Mesmo } \\
\text { depois de conhecerem a senhora, minha mãe, } \\
\text { eles não acreditavam. Tenho pra mim que eles } \\
\text { pensavam que eu tinha uma babá mulata mes- } \\
\text { mo. Desde que eu comecei a me passar por } \\
\text { branco, ninguém nunca duvidou que eu sou } \\
\text { branco. No meu trabalho, o chefe é do Sul e ele } \\
\text { sempre fica xingando negros na minha presen- } \\
\text { ça, nem sonha que eu também sou um deles. } \\
\text { Só rindo mesmo! }\end{array}$ \\
\hline
\end{tabular}

Nas escolhas tradutórias realizadas no texto-alvo, tivemos de nos ater a um elemento norteador que era estabelecer um limite de escolha desses termos de acordo com as discussões existentes no contexto-alvo e, portanto, evitar a escolha de termos altamente ofensivos que não estejam condizentes com aqueles expressos no texto-fonte. Consequentemente, propomos traduzir os termos respeitando a Letra de um modo comprometido com as significações e leituras oferecidas pelo texto, mas que não ultrapasse os limites que o próprio texto-fonte apresenta. Mas também é importante considerar que o texto-fonte foi escrito em uma época em que as discussões e reflexões sobre termos referentes à raça estavam começando, 
logo, alguns deles eram utilizados à época, também discutidos e, posteriormente, foram rediscutidos e caíram em desuso, como, por exemplo, "Negro", "Mullatto" e "Colored", como pode ser verificado no dicionário Merriam-Webster. Em sua definição do termo "colored": no início de algumas entradas aparece "(termo) datado, hoje ofensivo" ". Muitos dos termos que aparecem na rede significante do texto-fonte são considerados datados e ofensivos em relação à época atual.

No início do século XX havia a discussão do termo colored, que era um termo considerado ofensivo e que apontava para como os brancos rotulavam as pessoas negras. W. E. B Du Bois, importante intelectual afro-americano, defendia o emprego da palavra negro. Com o passar do tempo, já na década de 1960, este termo (negro) passou a ser rediscutido também e se defendia o uso de black, person of color, african-american e esta discussão sobre a adequação de termos chega até os dias atuais ${ }^{56}$. Esta discussão dos termos entre as pessoas negras tem como propósito principal expressar sua autoafirmação e identidade.

Há também a questão da escolha do autor. Um dos fatos que pode sinalizar isto aparece na autobiografia de Langston Hughes, I Wonder as I Wander (1956), que aborda a vida do autor durante a década de 1930. Após uma viagem a Cuba, Hughes escuta músicas de rumba e percebe a multiplicidade de tons de pele negra expressas nas letras. Ele presta atenção às letras das canções de amor, nas quais as nuances de tom de pele eram abordadas ao descrever as mulheres (mi negra, mi morena, my chocolate sweetie ou mulatto beauty (HUGHES, 1993, p. 10). Ele observa que estas nuanças não eram expressas na tradução que se faziam destas canções para a Broadway para o consumo americano. Estes termos aparecem com bastante frequência nos contos da obra The Ways of White Folks e não é diferente no conto "Passing". Podemos conjecturar se o autor tentou incorporar esta ideia ao seu trabalho e se o que é apresentado neste sentido seria uma influência desta característica das canções, percebida pelo autor.

Refletir sobre a questão de termos raciais, sua discussão ao longo do tempo e como isto reverbera na tradução também têm por base as concepções de uma tradução pós-colonialista. O tradutor, neste sentido, propõe um novo texto que irá atuar em uma nova construção sócio-histórica e não poderia pressupor que

4 Cf.https://www.merriam-webster.com/dictionary/colored. Acesso em 30out2020.

5 Cf. https://edition.cnn.com/2014/02/19/living/biracial-black-identity-answers/index.html. Acesso em 23out2020.

6 Cf. https://www.ferris.edu/HTMLS/news/jimcrow/question/2010/october.htm. Acesso em 23 out 2020 . 
uma rede de significantes, tal qual a proposta em 1934, poderia funcionar hoje. Como afirma Ovidi Carbonell i Cortés (1997), o tradutor não lida com a pura transposição de conceitos, ele é parte fundamental na lógica em que um texto chega a uma outra cultura e como ele é lido e aceito nela. A tradução em si é uma atividade que está inserida em uma determinada ideologia do contexto de chegada e é um lugar instável, no qual há um conflito de representações, uma hibridização, um espaço de litígio.

Um fato a ser mencionado na rede de significantes do texto-alvo é a repetição de "negro" como tradução para "negro", "black" (e, em um momento, para a tradução de "colored"). Na tradução prosposta, as duas primeiras palavras são traduzidas desta forma e, como exemplo, podemos mencionar a tradução do título do documentário I'm not your Negro (2016), de Raoul Peck, para "Eu não sou seu Negro" no Brasil. Seguindo escolha tradutória, preferimos manter um único significante no texto traduzido para dois significantes do texto-fonte, diminuindo o número de elementos da rede, mas mantendo uma determinada coerência na tradução a partir das escolhas existentes na língua-alvo. Quanto a este aspecto, podemos verificar o que Carbonell i Cortés afirma: "A tradução entre culturas põe em jogo uma série de tensões que possibilitam a produção do significado estrangeiro na cultura de destino. Essas tensões estão determinadas pelas estruturas de recepção, e o texto traduzido cumprirá a função requerida por elas”" (1997, p. 31, tradução minha). O trabalho de tradução se dá entre duas culturas, mesmo que a função do texto seja determinada pela cultura-alvo, portanto, pensamos neste espaço de tensões entre duas culturas e dentro das duas culturas e tentamos produzir algum significado a partir das escolhas de tradução no texto reescrito. Preferimos nos ater a uma escolha existente, mantendo uma rede de significantes que faça sentido na recepção do texto traduzido.

Podemos apontar também como uma rede significante permite identificar outros significantes, que acrescentam mais camadas de interpretação. Estes significantes que detectamos estão relacionados à ideologias e discursos raciais. Isto se dá, por exemplo, na presença de "darkies", que é o diminutivo de 'dark', mas o diminutivo é utilizado com um eufemismo ou uma docilização ao falar do individuo negro.

7 [la traducción entre culturas pone en juego toda una serie de tensiones que posibilitan la producción del significado ajeno en la cultura de destino. Estas tensiones están determinadas por las estructuras de recepción, y el texto traducido inevitablemente va a cumplir la función requerida por ellas] 
Outro exemplo é o par "colored -> balf-colored" que aponta justamente para a questão racial nos Estados Unidos. A One Drop Rule (Regra da gota de sangue única ${ }^{8}$ é uma questão histórico-cultural daquele país. Lauro Maia Amorim (2012) define o termo: "qualquer pessoa com histórico de ascendência africana, ainda que minimamente visível ou até mesmo invisível aos olhos, deveria ser considerada negra" (p. 117). Ser balf-colored, neste sentido, significa dizer que você é "metade negro" (tradução literal), mesmo tendo a pele branca assim como o personagem Jack, remetente da carta. Utilizamos "parte negro" com base na dublagem da série Todo Mundo Odeia o Chris (2005), no qual a escolha realizada pareceu satisfatória para ser utilizada aqui. Na fala do personagem Greg, ele afirma ser "an octoroon”, um termo de uso mais antigo e ofensivo, que significa ser $1 / 8$ negro (ter um tataravô negro $)^{9}$ e foi traduzido dessa maneira na dublagem. Portanto, decidimos seguir a ideia e utilizar "parte negro" (não traduzindo colored para "de cor" e tendo, por fim, "parte de cor"). Abaixo segue um quadro com essas escolhas.

Quadro 5 - Significantes e outras significações

\begin{tabular}{|l|l|}
\hline Dark $->$ darkies (eufemismo) & Escuro $->$ escurinhos \\
\hline Colored $->$ half-colored (questão racial) & De cor/negro $->$ parte negro \\
\hline
\end{tabular}

Há também uma outra rede de significantes que aponta para a temática racial e da discriminação no que diz respeito a certas concepções institucionalizadas na sociedade, isto é, expressões preconceituosas naturalizadas no uso linguístico. Por exemplo, em "mire of color" a primeira acepção presente no dicionário The Free dictionary é: "Uma área de terra molhada, lamacenta; um pântano"10, que poderia ser traduzido para "lamaçal" em uma escolha mais literal. Porém, optamos pela terceira acepção do termo no dicionário, que se refere, em sentido figurado, a uma condição ou situação em que um indivíduo está em desvantagem”. Tendo isto em vista, traduzimos este termo para "armadilha" pelo fato de ele trazer uma noção de que um indivíduo evita correr o risco de estar preso em uma situação difícil. No conto, esta situação difícil decorreria da descoberta por outras pessoas que Jack é, na verdade, negro. Na tabela abaixo as apresentamos com suas respectivas traduções.

8 Termo traduzido por Lauro Maia Amorim em seu artigo "O papel da tradução na construção da identidade da literatura afro-americana no Brasil” (2012, p. 117).

9 Cf. https://www.dictionary.com/browse/octoroon. Acesso em 28mai2020.

10 Cf. https://www.thefreedictionary.com/mire. Acesso em 30out2020. 
Quadro 6 - Rede significantes - concepções institucionalizadas do preconceito racial

\begin{tabular}{|l|l|}
\hline Good hair & Cabelo bom \\
\hline White world & Mundo dos brancos \\
\hline Marry white & Casar como branco \\
\hline Live white & Viver como branco \\
\hline Mire of color & Armadilha da cor \\
\hline
\end{tabular}

\section{Quadro 7 - exemplos: texto-fonte e texto-alvo}

\begin{tabular}{|c|c|}
\hline Texto-fonte & Texto-alvo \\
\hline $\begin{array}{l}\text { I hope Charlie and Gladys don't feel bad } \\
\text { about me. It's funny I was the only one of the } \\
\text { kids light enough to pass. Charlie's darker than } \\
\text { you, even, Ma. I know he sort of resented it } \\
\text { in school when the teachers used to take me } \\
\text { for white, before they knew we were brothers. } \\
\text { I used to feel bad about it, too, then. But now } \\
\text { I'm glad you backed me up, and told me to } \\
\text { go ahead and get all I could out of life. That's } \\
\text { what I'm going to do, Ma. I'm going to marry } \\
\text { white and live white, and if any of my kids are } \\
\text { born dark I'll swear they aren't mine. I won't } \\
\text { get caught in the mire of color again. Not me. } \\
\text { I'm free, Ma, free! }\end{array}$ & $\begin{array}{l}\text { Espero que Charlie e Gladys não fiquem } \\
\text { com raiva de mim. É engraçado, eu sou o único } \\
\text { dos filhos que é claro o suficiente pra passar } \\
\text { por branco. Charlie consegue ser ainda mais } \\
\text { escuro do que você, mãezinha. Eu sei que ele } \\
\text { ficava meio chateado na escola quando os pro- } \\
\text { fessores achavam que eu era branco, antes de } \\
\text { saberem que a gente era irmão. Eu ficava me } \\
\text { sentindo mal também, nessa época. Mas agora } \\
\text { fico feliz que você me apoiou e me disse pra ir } \\
\text { em frente e aproveitar tudo o que a vida pode } \\
\text { me oferecer. É isso o que eu vou fazer, mãezi- } \\
\text { nha. Vou me casar como branco e viver como } \\
\text { branco e se algum dos meus filhos nascer es- } \\
\text { curo, vou jurar que não é meu. Não vou ficar } \\
\text { preso nessa armadilha da cor de novo. Eu não. } \\
\text { Eu sou livre, mãezinha, livre! }\end{array}$ \\
\hline
\end{tabular}

Estas características detectadas na prosa nos permitem compreender que este não é apenas um gênero de uso comum, sem a presença de qualquer espécie de poeticidade ou literariedade. Pelo contrário, a prosa, assim como a poesia, possui um investimento em seu arranjo que influencia tanto a sua leitura quanto a sua tradução. Mesmo não dependendo tanto de uma certa rigidez na organização formal, a organização vocabular é parte da construção do texto e é determinante. As relações que a Letra estabelece no texto-fonte são recriadas na tradução, o que confere literariedade ao texto-alvo. O papel da tradução como reescrita é estabelecer estas relações que, por sua vez, veiculam significados e permitem interpretações. 


\section{Oralidade em "Passing"}

No que diz respeito à oralidade, em "Passing" é possível perceber um registro mais baixo, informal, justamente por se tratar de uma carta familiar. Um fator que aparece logo a princípio é o uso de formas contratas (contract forms) ao longo de todo o texto, mais associadas à linguagem falada da língua inglesa. Como o gênero epistolar pressupõe esse tom conversacional, isto se mostra a partir desse aspecto, como podemos demonstrar através do seguinte fragmento: "But, Ma, I felt mighty bad about last night. The first time we'd met in public that way. That's the kind of thing that makes passing hard, having to deny your own family when you see them" (Hughes, 1934, s.p., grifos meus). Outros elementos textuais que podemos apontar como indicadores de um registro mais baixo são "the kind of thing" e "mighty". Segundo o Cambridge Online Dictionary, "mighty" é um advérbio utilizado em um registro mais informal do inglês americano ${ }^{11}$. O uso de expressões típicas da fala também aparece como no segmento "(...) I sometimes get a kick out of putting something over on the boss (...)". A expressão "To get a kick out" significa obter uma grande alegria de fazer algo ${ }^{12}$ e "putting something over" significa enganar alguém. Além disso há palavras como "well fixed” (pessoas com nível social estável), "gee” (puxa vida), "to queer me" (estragar os planos), que também aparecem como elementos que mostram um registro mais informal, dando ao leitor a possibilidade de imersão naquela realidade através da familiaridade que esses elementos linguísticos evocam, como se o leitor fizesse parte daquela correspondência e não estivesse distante daquele grupo e das situações evocadas.

Algumas repetições que valem ser mencionadas no conto são as repetições tanto de $M a$, vocativo que o filho utiliza com muita frequência no decorrer do conto, quanto da conjunção but. Este ato de repetir palavras aponta para uma escrita mais descuidada, que não se atém à rigidez da escrita formal, que tem por exigência evitar este tipo de repetição. Além disso, podemos concluir que este descuido com a forma indica o tom conversacional que a carta possui, conforme mencionado anteriormente; em uma conversa esta característica é marcante e tentamos mantê-la no texto-alvo.

$\mathrm{Na}$ tradução propomos inicialmente o uso de "pra"/pro ao invés de "para"/ "para o" a fim de evocar um registro mais baixo e um tom conversacional. Outra

11 Cf. https://dictionary.cambridge.org/pt/dicionario/ingles/mighty. Acesso em 28mai2020.

12 Cf. https://idioms.thefreedictionary.com/get+a+kick+out + of. Acesso em 29mai2020. 
escolha que aponta para a linguagem falada do português brasileiro é o uso de pronome sujeito como objeto como em "contratar ele" (FIGUEIREDO, 2009, p. 409).

Outras escolhas vocabulares seguem: repetição de pronome pessoal, o uso de "a gente" ao invés de "nós", uso de "né?" ao invés de "não é?". Estas escolhas vocabulares procuram transmitir no texto-alvo esta familiaridade, o não engessamento do texto pela formalidade e, portanto, permitir que um tom mais informal viesse à tona na carta. Estas escolhas podem ser verificadas no quadro abaixo. Em alguns momentos, uma correspondência direta entre texto-fonte e alvo não foi possível de ser realizada, então inserimos nossas escolhas que evocam a oralidade em outra passagem do conto, realizando uma compensação. 
Quadro 8- escolhas vocabulares que evocam um registro mais informal nos textos fonte e alvo

\begin{tabular}{|c|}
\hline Texto-fonte \\
\hline $\begin{array}{l}\text { Funny thing, though, Ma, how some white } \\
\text { people certainly don't like colored people, do } \\
\text { they? (If they did, then I wouldn't have to be } \\
\text { passing to keep my good job.) They go out of } \\
\text { their way sometimes to say bad things about } \\
\text { colored folks, putting it out that all of us are } \\
\text { thieves and liars, or else diseased - consump- } \\
\text { tion and syphilis, and the like. No wonder it's } \\
\text { hard for a black man to get a good job with the } \\
\text { kind of false propaganda going around. I nev- } \\
\text { er knew they made a practice of saying such } \\
\text { terrible things about us until I started passing } \\
\text { and heard their conversations and lived their } \\
\text { life. }\end{array}$ \\
\hline
\end{tabular}

But I don't mind being "white”, Ma, and it was mighty generous of you to urge me to go ahead and make use of my light skin and good hair. It got me this job, Ma, where I still get $\$ 65$ a week in spite of the depression. And I'm in line for promotion to the chief office secretary, if Mr. Weeks goes to Washington. When I look at the colored boy porter who sweeps out the office, I think that's what I might be doing if I wasn't lightskinned enough to get by. No matter how smart that boy'd get to be, they wouldn't hire him for a clerk in the office, not if they knew it. Only for a porter. That's why I sometimes get a kick out of putting something over on the boss, who never dreams he's got a colored secretary.

But, Ma, I felt mighty bad about last night. The first time we'd met in public that way. That's the kind of thing that makes passing hard, having to deny your own family when you see them. Of course, I know you and I both realize it is all for the best, but anyhow it's terrible. I love you, Ma, and hate to do it, even if you say you don't mind.
Texto-alvo

Uma coisa engraçada, mãezinha, é como alguns brancos realmente não gostam de pessoas de cor, né? (Se gostassem, eu não teria que estar me passando por branco pra manter meu bom emprego). Eles exageram às vezes quando falam coisas ruins sobre pessoas de cor, ficam dizendo que todos nós somos ladrões e mentirosos, ou cheios de doenças - tuberculose ou sífilis, entre outras coisas. Não é de se admirar a dificuldade pra um homem negro de conseguir um bom trabalho com esse tipo de propaganda falsa aí na praça. Eu não sabia que eles tinham o costume de dizer coisas tão horríveis sobre a gente até começar a me passar por branco, ouvir a conversa deles e viver a vida deles.

Mas não me importo de ser "branco", mãezinha, e foi muita bondade da senhora insistir pra eu ir em frente e fazer uso da minha pele clara e do meu cabelo bom. Foi o que me permitiu ter esse emprego, onde eu ainda ganho 65 dólares por semana apesar da Depressão. E eu sou o próximo na fila pra ser promovido a secretário-chefe se o senhor Weeks for pra Washington. Quando eu olho pro garoto de cor que varre o escritório, fico pensando que esse seria o meu trabalho se eu não tivesse a pele clara o suficiente pra passar despercebido. Não importa se esse garoto é inteligente, eles nunca vão contratar ele pra secretário, não se eles souberem de sua cor. Só pra porteiro mesmo. É por isso que às vezes eu fico feliz da vida de tapear o chefe, ele que nem sonha que tem um funcionário de cor.

Mas, mãezinha, eu me senti muito mal quanto a ontem à noite. A primeira vez que a gente se encontrou em público daquele jeito. Coisas assim é que fazem se passar por branco ser difícil, ter que renegar sua própria família quando a vê. Claro, eu sei que nós dois vemos isso como o melhor a ser feito, mas, de qualquer maneira, é horrível. Mãezinha, eu te amo, e odeio fazer isso tudo, mesmo você dizendo que não se importa. 
Neste sentido, a oralidade em "Passing" aponta para a familiaridade e simplicidade. Mas não se pode dizer que seja uma simplicidade desmotivada ou inútil. Podemos perceber a ação de utilizar um gênero textual tradicional e cotidiano como atitude política de denúncia e confronto a uma determinada realidade. Esta familiaridade que a oralidade apresenta no gênero epistolar aproxima o leitor das ideias veiculadas no texto e promove, ao mesmo tempo, uma identificação de um leitor que porventura passe ou presencie uma dentre tantas situações relatadas por Jack, o filho que "passa por branco".

Outro aspecto a ser mencionado no conto é a quase nula utilização do inglês afro-americano, como é possível perceber em outros contos de The Ways of White. Na seguinte frase, em toda a carta, o traço do inglês afro-americano se apresenta de maneira mais visível na sintaxe da oração: "But you was too proud, wasn't you, Ma?" (Hughes, 1934, s.p., grifo meu), na qual o pronome you concorda com was e não com were conforme recomenda a norma da língua inglesa ${ }^{13}$. Com este detalhe da oralidade do personagem, podemos interpretar que o filho está tão imerso neste "mundo dos brancos" que se afastou de suas origens ao não mais adotar a variedade linguística.

No texto-alvo que propusemos, por exemplo, não chegamos a uma inserção garantida de um elemento linguístico que seja parte de uma variedade e que indique na fala do indivíduo a diferença entre sua origem (um indivíduo filho de mãe negra e pai branco) e o grupo no qual se inseriu posteriormente (de pessoas brancas). No contexto-alvo não temos uma diferença entre variedades linguísticas associadas especificamente a grupos étnicos (LUCCHESI, 2009, p. 31-32). Optamos, portanto, por traços do português brasileiro que são considerados não-padrão, parte da linguagem falada (como o exemplo citado anteriormente, o emprego de pronome sujeito como objeto em "contratar ele" ao invés de "contratá-lo") de forma a veicular esta diferença. Pensando no processo de tradução numa leitura pós-colonial, entendemos o que Carbonell i Cortés afirma sobre a tradução estar em um entre-lugar, ser uma tarefa que ressitua o texto-fonte em uma nova cultura e sociedade que, por sua vez, possui regras e estratégias discursivas distintas (1997, p. 23). Além disso, entendemos que o trabalho do tradutor é entender como a língua funciona e tentar expressar ocorrências que aparecem no texto-fonte em sua tradução, sem se deixar influenciar por preconceitos linguísticos infundados que o impedem de optar por fatores linguísticos legítimos e expressar a pluralidade da língua no texto-alvo.

13 Cf. https://www.todamateria.com.br/was-e-were/. Acesso em 26mai2020. 


\section{Conclusão}

Com estas análises e reflexões pudemos chegar a algumas conclusões. Consideramos os preceitos do trabalho de tradução em um contexto pós-colonial, na qual o texto traduzido assume uma função no contexto-alvo, que possui sua própria lógica sócio-histórica e político-ideológica. Por tratar-se de um texto que lida com uma problemática humana, historicamente institucionalizada e que tenta trazer uma discussão crítica sobre a mesma através do uso de uma linguagem mais próxima da fala e do leitor, pensamos que seria necessário pensar em um texto que funcionasse no contexto-alvo, que trouxesse tais críticas e que também evocasse essa proximidade.

Além disso, pensamos que a tradução entre culturas deve considerar ambas, tanto as possibilidades que a cultura-fonte oferece e os limites que a cultura-alvo apresenta para abrigá-las. Estrangeirizar ou domesticar ganha novos horizontes de reflexão tradutória, novas perspectivas na escolha direta, pois o tradutor lida com diversos elementos de ordem externa ao texto, principalmente ideológicos e políticos, que o constituem e que constituem os leitores. Logo, em um texto como esse, o tradutor precisa ser sensível o suficiente para traçar um projeto de tradução que contemple estas condições.

Além disso, este texto permite a compreensão de que os textos ficcionais em prosa também apresentam um investimento criativo em sua forma, eles não são compostos apenas de um conteúdo narrativo que deve ser priorizado como o mais importante. A construção de um texto literário, seja em prosa ou em verso, traz investimento formal ao qual o tradutor precisa estar atento a fim de propor um texto-alvo igualmente literário e não apenas uma decodificação do conteúdo.

\section{Referências bibliográficas}

AFRICAN AMERICAN ENGLISH. Disponível em: https://www.uni-due.de/SVE/ VARS_AfricanAmericanEnglish.htm. Acesso em: 20 maio 2020.

ALVES, Márcio Miranda. "Querida filha, queridos pais: o uso da carta na ficção de Érico Veríssimo”. In: Letrônica. Porto Alegre: Vol. 8, No. 1, 2015. pp. 182-194.

AMORIM, Lauro Maia. "O papel da tradução na construção da identidade da literatura afro-americana no Brasil”. In: Revista do GEL. São Paulo, Vol. 9, No. 1, 2012. pp. 107-134. BAGNO, Marcos. Nada na língua é por acaso: por uma pedagogia da variação linguística. $1^{a}$ Ed. $6^{a}$ reimpressão. São Paulo: Parábola Editorial, 2007. 
BERMAN, Antoine. A tradução e a letra ou o albergue do longínquo. Trad. Andréia Guerini, Marie-Hélène C. Torres e Mauri Furlan. 2. ed. Florianópolis: PGET/UFSC, 2013.

BRITTO, Paulo Henriques. A Tradução Literária. Rio de Janeiro: Civilização Brasileira, 2012.

CARBONELL I CORTÉS, Ovidi. Traducir al otro: Traducción, exotismo, poscolonialismo. Cuenca: Ediciones de la Universidade de Castilla - La Mancha, 1997, p. 19-57.

CHKLOVSKI, Viktor. A arte como procedimento. In: EIKHENBAUM et al. Teoria da literatura - formalistas russos. Porto Alegre: Editora Globo, 1978. p. 39-56.

COLORED. Webster's Third New International Dictionary, Unabridged. Disponível em: https://www.merriam-webster.com/dictionary/colored. Acesso em 30out2020.

DIAS, Laice Raquel. Gêneros textuais para a produção de textos escritos no livro didático. Anais do SIELP. Uberlândia: EDUFU, Vol. 2, No. 1, 2012. Disponível em: http:/ /www. ileel.ufu.br/anaisdosielp/wp-content/uploads/2014/07/volume_2_artigo_166.pdf.

EVEN-ZOHAR, Itamar. Polysystem Theory. In: . Papers in Culture Research. Tel Aviv: Porter Chair of Semantics, 2005.

FIGUEIREDO, Cristina. O objeto direto anafórico: a categoria vazia e o pronome lexical. IN: LUCCHESI, Dante; BAXTER, Alan; RIBEIRO, Ilza (Org). O Português afrobrasileiro. Salvador: EDFUBA, 2009, p. 409.

GET A KICK OUT OF. The Free Dictionary.com. Farlex, Inc. Página eletrônica: https:// idioms.thefreedictionary.com/get $+\mathrm{a}+$ kick + out + of. Acesso em 29 mai2020.

GRANT, Nathan. Hughes/Lawrence/Douglass: Power and Resistance in The Ways of White Folks. Afro-Americans in New York Life and History. Nova Iorque, v. 19, n. 2, p. 43- 48, 1995.

HATIM, Basil. The translation of style: linguistic markedness and textual evaluativeness. In: Journal of Applied Linguistics. S.l., Vol. 1, No. 3, 2004. pp. 229-246.

HUGHES, Langston. Passing. In: ___ The ways of white folks. Nova York: Vintage Books - Random House Inc., 1990, s.p. (Vintage Classics Edition). Pdf.

HUGHES, Langston. I wonder as I wander: An autobiographical journey. Nova York: Hill and Wang, 1993. p. 10.

I AM not your Negro. Direção: Raoul Peck. Intérprete: Samuel L. Jackson. Estados Unidos, Suíça, França, Bélgica: Magnolia Pictures, 2017. (96 min).

JONES, Martha S. WHAT'S IN A NAME? 'MIXED', BIRACLAL', BLACK'. CNN. Disponível em: https://edition.cnn.com/2014/02/19/living/biracial-black-identity-answers/index.html. Acesso em 23out2020.

KOHLRAUSCH, Regina. "Gênero epistolar: a carta na literatura, a literatura na carta, rede de sociabilidade, escrita de si...”. In: Letrônica. Porto Alegre: v. 8, n. 1, 2015. pp. 148-155. KUTZINKSI. Vera M. The Worlds of Langton Hughes: Modernism and Translation in the Americas. Nova Iorque: Cornell University Press, 2012. 
LUCCHESI, Dante. Introdução. In: LUCCHESI, Dante; BAXTER, Alan; RIBEIRO, Ilza (Org.). O Português afrobrasileiro. Salvador: EDFUBA, 2009, p. 31-32.

MARINHO, Fernando. "Carta pessoal”; Brasil Escola. Página eletrônica: https:/ / brasilescola.uol.com.br/redacao/carta-pessoal.htm. Consulta realizada em 30mai2020.

MIRE. American Heritage ${ }^{\circledR}$ Dictionary of the English Language, Fifth Edition. 2016. Houghton Mifflin Harcourt Publishing Company. Página eletrônica: https://www.thefreedictionary.com/mire. Consulta realizada em 28mai2020.

MIGHTY. CAMBRIDGE Dictionary. Cambridge University Press, 2020. Página eletrônica: https://dictionary.cambridge.org/pt/dicionario/ingles/mighty. Consulta realizada em 28 mai2020.

MULATTO. Webster's Third New International Dictionary, Unabridged. Página eletrônica: https://www.merriam-webster.com/dictionary/mulatto. Consulta realizada em 28 mai2020.

NEGRO. Webster's Third New International Dictionary, Unabridged. Página eletrônica: https://www.merriam-webster.com/dictionary/Negro. Consulta realizada em 28 mai2020.

OCTOROON. Dictionary.com. 2020. Página eletrônica: < https://www.dictionary.com/ browse/octoroon>. Consulta realizada em 28 mai2020.

OSTROM, Hans. The Ways of White Folks. Overview: The genesis and achievement of The Ways of White Folks. In: __ Langston Hughes: a story of the short fiction. Nova Iorque: Twayne Publishers, 1993, p. 3-18.

PAGANINE, Carolina. "Tradução Comentada: o gótico e a cadeia de significantes". In: Belas Infiéis. Brasília, Vol. 2, No. 1, 2013. pp. 251-264.

PEREIRA, Iuri. "Dez cartas jesuíticas". In: Novos estud. - CEBRAP. São Paulo, No. 79, 2007. pp. 267-272.

RAMPERSAD, Arnold. Chronology. In: McLAREN, Joseph (Org.).The Collected Works of Langston Hughes: Authobiography: I Wonder as I Wander. Columbia e Londres: University of Missouri Press, 2003, p. xi-xvi.

ROCHA, Vanessa Massoni da. "Notas e apontamentos sobre o protocolo de leitura do epistolar". In: Revista de Letras. São Paulo, Vol. 51, No. 1, 2011. pp. 109-125.

ROSA, Alexandra Assis. "Translating orality, recreating otherness". In: Translation Studies. S.l., Vol. 8, No. 2, 2015. pp. 209-225.

SAMPSON, Henry T. Blacks in Blackface: A sourcebook on Early Black Musical Shows. Plymouth: The Scarecrow Press, Inc, 2014.

SAUSSURE, Ferdinand de. Curso de Lingüística Geral. 2. ed. São Paulo: Cultrix, 2006.

SILVA, Daniele Cristina Agostinho da. Epístola. Página eletrônica: https://www.infoescola. com/literatura/epistola/. Consulta realizada em 30mai2020.

SINGAL, Daniel Joseph. "Towards a Definition of American Modernism". In: American Quarterly. Vol. 39, No. 1, 1987. pp. 7-26. 
THE BIOGRAPHY.COM WEBSITE. Langston Hughes Biography. Página eletrônica: <http://www.biography.com/people/langston-hughes-9346313\#related-video-gallery>. Consulta realizada em 25 fev 2020.

TIN, Emerson (Org.). A arte de escrever cartas: Anônimo de Bolonha, Erasmo de Rotterdam, Justo Lípsio. Campinas, SP: Editora da UNICAMP, 2005.

TODA MATÉRIA. Página eletrônica: < https://www.todamateria.com.br/was-e-were/>. Consulta realizada em 26mai2020.

TODO mundo odeia o Chris, primeira temporada. Criação: Chris Rock, Ali Le Roi. Estados Unidos: CR Enterprises Inc.; 3 Arts Entertainment; Paramount Television; CBS Paramount Television, 2005. 22 min, son., col.

WHEN DID THE WORD NEGRO BECOME SOCIALLY UNACCEPTABLE?. 2010. Jim Crow Museum of Racist Memorabilia. Disponível em: https:/ /www.ferris.edu/ HTMLS/news/jimcrow/question/2010/october.htm. Acesso em 23out2020. 